\title{
Robótica Educativa e Scratch na perspectiva de projeto na educação básica para desenvolvimento do pensamento computacional frente a cultura digital
}

\author{
Educational Robotics and Scratch from the perspective of a basic education project for the \\ development of computational thinking in the face of digital culture \\ Robótica Educativa y Scratch desde la perspectiva de un proyecto de educación básica para el \\ desarrollo del pensamiento computacional de cara a la cultura digital
}

Recebido: 18/02/2021 | Revisado: 28/02/2021 | Aceito: 05/03/2021 | Publicado: 12/03/2021

Mara Regina Rosa Radaelli

ORCID: https://orcid.org/0000-0002-5519-2922 Universidade Federal de Santa Maria, Brasil E-mail: maradaelli@gmeil.com

Mario Vásquez Astudillo

ORCID: https://orcid.org/0000-0003-3665-1123 Universidade Federal de Santa Maria, Brasil E-mail: mario.astudillo@ufsm.br

Alexandre Abreu de Paula

ORCID: https://orcid.org/0000-0002-8730-2022 Universidade Federal de Santa Maria, Brasil

E-mail: alexandredepaula@gmail.com

Ricardo Radaelli Meira

ORCID: https://orcid.org/0000-0002-4922-2267 Instituto Federal de Educação, Ciência e Tecnologia do Sul-Rio-Grandense, Brasil E-mail: ricardoradaelli@gmail.com

\begin{abstract}
Resumo
O presente artigo tem por objetivo compartilhar os resultados de uma pesquisa-ação do projeto piloto de Robótica Educativa e de Scratch para alunos da educação Básica, dos anos finais do Ensino Fundamental, desenvolvido em uma escola pública estadual no Município de Cruz Alta RS, Brasil. O projeto foi pensado e organizado frente ao contexto da cultura digital em que os alunos estão inseridos, pensado no formato de oficinas, envolvendo atividades práticas. O estudo pautou-se em noções práticas de Robótica Educativa a partir de sucatas e do pensamento computacional apoiado nas ferramentas de interatividade do Software Scratch. No decorrer das oficinas práticas, observou-se o interesse e a fluência dos alunos que participaram do projeto. As oficinas aconteceram no turno inverso das aulas regulares dos alunos. Foram um total de quinze encontros, no decorrer de quatro meses. O estudo foi guiado pelo objetivo de explorar o conhecimento já adquiridos pelos alunos, por meio, de suas vivências frente a cultura digital e por meio de noções de Robótica Educativa e do pensamento computacional, como incentivo para despertar a motivação à novas competências como a compreensão, o pensar, o buscar soluções, a criatividade, julgamento, tomada de decisões, cooperação e colaboração no trabalho em grupo. São descritas as oficinas, seus objetivos e as observaçães, em relação a motivação e a aquisição de habilidades e competências, enquanto a realização das atividades propostas, em cada uma, bem como, a percepção de conhecimentos prévios dos alunos na resolução de problemas.
\end{abstract}

Palavras-chave: Ensino; Pensamento computacional; Tecnologias; Competências; Habilidades; Robótica educativa; Scratch.

\begin{abstract}
This article aims to share the results of an action research of the Educational Robotics and Scratch pilot project for students of Basic Education, in the final years of Elementary School, developed in a state public school in the municipality of Cruz Alta RS, Brazil. The project was designed and organized in the context of the digital culture in which students are inserted, designed in the format of workshops, involving practical activities. The study was based on practical notions of Educational Robotics based on scraps and computational thinking supported by the interactivity tools of the Scratch Software. During the practical workshops, the interest and fluency of the students who participated in the project were observed. The workshops took place on the reverse shift of the students' regular classes. There were a total of fifteen meetings, over the course of four months. The study was guided by the objective of exploring the knowledge already acquired by students, through their experiences in the face of digital culture and
\end{abstract}


through notions of Educational Robotics and computational thinking, as an incentive to awaken the motivation to new skills such as understanding, thinking, looking for solutions, creativity, judgment, decision making, cooperation and collaboration in group work. The workshops, their objectives and observations are described, in relation to motivation and the acquisition of skills and competences, while the performance of the proposed activities in each one, as well as the perception of students' prior knowledge in problem solving.

Keywords: Teaching; Computational thinking; Technologies; Competence; Skills; Educational robotics; Scratch.

\section{Resumen}

Este artículo tiene como objetivo compartir los resultados de la investigación-acción del proyecto piloto de Robótica Educativa y Scratch para estudiantes de Educación Básica, en los últimos años de la Escuela Primaria, desarrollado en una escuela pública estatal en el municipio de Cruz Alta RS, Brasil. El proyecto fue diseñado y organizado en el contexto de la cultura digital en la que se insertan los estudiantes, diseñado en formato de talleres, involucrando actividades prácticas. El estudio se basó en nociones prácticas de Robótica Educativa basadas en scraps y pensamiento computacional apoyados por las herramientas de interactividad del Software Scratch. Durante los talleres prácticos se observó el interés y la fluidez de los alumnos que participaron en el proyecto. Los talleres tuvieron lugar en el turno inverso de las clases regulares de los estudiantes. Hubo un total de quince reuniones a lo largo de cuatro meses. El estudio estuvo guiado por el objetivo de explorar los conocimientos ya adquiridos por los estudiantes, a través de sus vivencias frente a la cultura digital y a través de nociones de Robótica Educativa y pensamiento computacional, como incentivo para despertar la motivación hacia nuevas habilidades como la comprensión, el pensamiento, buscando soluciones, creatividad, juicio, toma de decisiones, cooperación y colaboración en el trabajo en grupo. Se describen los talleres, sus objetivos y observaciones, en relación con la motivación y la adquisición de habilidades y competencias, así como el desempeño de las actividades propuestas en cada uno, así como la percepción de los conocimientos previos de los estudiantes en la resolución de problemas.

Palabras clave: Ensenãnza; Pensamiento computacional; Tecnologías; Competencia; Habilidades; Robótica educativa; Scratch.

\section{Introdução}

Os avanços tecnológicos, o acesso à informação e sua veiculação, a universalização da cibercultura, a presença de tecnologias para fins pedagógicos, a inclusão digital nas escolas mediado por Políticas Públicas, as normatizações apresentadas na Base Nacional Comum Curricular (BNCC) e a massificação do uso de tecnologia móvel faz com que a comunidade escolar esteja inserida nos contextos tecnológicos e assim fazer uso destas nos processos de ensinar e de aprender.

Praticamente toda inovação em tecnologia da informação e comunicação são adaptadas para usos educacionais. Desde os cursos via rádio e correspondência até o presente com a proliferação de dispositivos móveis que nos faz aprender na palma de nossas mãos (Stumpenhorst, 2018).

Considerando este contexto e as diversas possibilidades de se estabelecer interações, fazem com que a cultura posta para essa geração de alunos, tenha que ser mais instigante, no que tange a área educacional, para que de maneira inovadora desperte a motivação do aluno para o aprender, e consequentemente, o conhecimento de como ele próprio aprende. Numa velocidade absurda que, por vezes, não conseguimos acompanhar, estão as inovações na área das tecnologias digitais da informação e da comunicação. O que não acontece com tamanha velocidade na área educacional, no que se refere ao uso de tais tecnologia para potencializar processos de ensino e de aprendizagem. As tecnologias digitais ficam rapidamente obsoletas. Não se trata de ganhar uma corrida tecnológica, mas de pensar quais são os enquadramentos pedagógicos mais adequados para que as tecnologias façam sentido (Castells, 2013; Quitián; González, 2020).

Recursos tecnológicos educacionais são pensados para potencializar a aprendizagem. As tecnologias educacionais se diversificaram, se modernizaram, tecnologias inovadoras já estão presentes em espaços educacionais, o que sugere processos constantes de atualizações metodológicas e pedagógicas.

Pensamentos novos, olhares novos para o como se faz o ensinar e o aprender, diante das possibilidades dos recursos das tecnologias digitais da informação e da comunicação na aprendizagem escolar. Considerando que tais tecnologias já são incorporadas para uso pessoal por grande maioria da comunidade escolar, isso, representa um fator potencializador para o processo de ensinar e o processo de aprender, utilizando-se destas. 
Com foco nesse contexto, tornou-se relevante organizar as oficinas com atividades para incentivar os alunos para o desenvolvimento do pensamento e do raciocínio lógico. Para isso elencou-se a Robótica Educativa com aproveitamento de sucatas e do software Scratch. "O diferencial da atividade de Robótica Educacional é que o erro é usado como parte do aprendizado" (Machado; Câmara; Willians, 2018, p. 217).

O incentivo para fomentar no aluno a pesquisa, a investigação e a aplicabilidade dos conhecimentos adquiridos ao longo de seus estudos através dos conteúdos curriculares, se tornaram ênfases no decorrer das oficinas para que se traduzisse em um aluno motivado e sociável. Para Cambruzzi e Souza (2015), a Robótica Educativa "[...] promove a socialização e a autonomia no aprendizado, criando um ambiente que reúne ciência, tecnologia e trabalho manual" (Cambruzzi; Souza, 2015, p. 23).

A Robótica Educativa cria possibilidade de desenvolvimento de técnicas e uso de programação; estimula o "raciocínio lógico; o espírito de cooperação; elevação do nível de concentração" (Mesquita; Albrecht, 2019, p. 23). Os alunos com atividades de Robótica Educativa aprendem não somente a construir um robô, desenvolvem habilidades de ordem superior (Rosa; Neto, 2020).

No foco educacional, a Robótica Educativa e o pensamento computacional foram usados neste projeto, como meio para um aprendizado baseado na prática cooperativa, com o objetivo também de desenvolver a capacidade de pensar, buscar soluções para atividades, bem como aos novos desafios propostos. Num trabalho cooperativo em grupo entre alunos e professores numa proposta interdisciplinar. Para Vicari, Moreira e Menezes (2018), o pensamento computacional na "[...] sua proposta, como metodologia, pode ser utilizada em várias áreas do conhecimento, ou seja, o PC é considerado transversal às demais ciências" (Vicari et al. (2018, p. 9-10).

\subsection{Pensamento computacional no ensino de programação}

O ensino de programação, defendida por Papert (1980), como forma de resolução de problemas cotidianos, se desenvolveu até as bases do Pensamento Computacional, definido por Wing (2006) como sendo a representação de habilidades e atitudes desenvolvidas com base nos processos da computação e que são aplicadas para a resolução de problemas comuns.

O Pensamento Computacional é uma habilidade fundamental para todos, assim como a capacidade de ler, escrever e resolver problemas aritméticos, dominar o pensamento computacional auxilia o indivíduo nos problemas cotidianos, tornando este, capaz de identificar e abordar os problemas de forma segmentada, facilitando sua resolução.

A computação e os computadores com base nos conceitos da ciência da computação, facilitam a difusão do pensamento computacional que envolve a solução de problemas, o projeto de sistemas e a compreensão do comportamento humano (Wing, 2006).

O pensamento computacional além de ser uma área recente, tem muito a ser explorado na área da educação, onde pode ser adotado na sala de aula nas práticas docentes durante todas as etapas e em consonância com a alfabetização e letramento digital, onde tem como conceitos de abstração; algoritmo; decomposição; e reconhecimento de padrões. (Quadros, 2020).

O uso de dispositivos eletrônicos assim com manuseio de aplicativos, não pode ser confundido com pensamento computacional, limitando a criatividade da mente humana. Pensamento computacional é "uma combinação do pensamento crítico com os fundamentos da Computação para resolver problemas, desenvolver sistemas e para entender o comportamento humano, habilidade fundamental para todos”. (Brackmann, 2017, pg. 27). 
Para Wing (2014), “o pensamento computacional é o processo de pensamento envolvido na formulação de um problema e na expressão de sua (s) solução (ões) de tal forma que um computador - humano ou máquina - possa executar com eficácia."

Problemas complexos são resolvidos através de conceitos e estratégias ligados ao computador com maneira de dividir em pequenos problemas simples, planejar antes, integrar partes de forma lógica e organizar as ideias de forma estrutural. Facilitando a mudança do pensamento para a linguagem do computador, auxiliando o aluno a desenvolver raciocínio lógico e abstrato (Zanetti, 2017).

Temos na educação básica a grande preocupação em ensinar o aluno a ler, escrever, somar e subtrair, tanto no Brasil como em outros países, com isso existem volumes de pesquisa educacional tanto análises estatísticas do desempenho dos alunos como trabalhos qualitativos sobre alfabetização (Blikstein, 2016).

Para Blikstein,

A lista de habilidades e conhecimentos necessários para o pleno exercício da cidadania no século XXI é tão extensa quanto controversa. Não sabemos muito bem quais são essas habilidades, muito menos como ensiná-las. [....], vamos discutir aquela que talvez seja a mais importante e menos compreendida dessas habilidades: o "pensamento computacional" (Blikstein, 2016).

$\mathrm{O}$ autor fala de uma pesquisa que mostra a facilidade de aprendizagem dos alunos em "ciência computacional", do que ciência tradicional (Blikstein, 2016). Vai além do uso das tecnologias, não dependendo delas, pois é um tipo de pensamento que compartilha características com o pensamento matemático, sistêmico e científico, usando as habilidades para solução de problemas e projetando e avaliando sistemas complexos (Paula; Valente; Burn, 2014).

O pensamento computacional faz um tratamento específico de pensar e analisar uma situação, inclusive influenciando várias áreas do conhecimento atual, tornando cada vez mais geral, global, universal. Isso faz argumentar que essa competência deveria ser adicionada às habilidades no processo educacional (Wing, 2008).

Temos no mundo digital, uma busca maior em desenvolver maior habilidades de raciocínio e capacidade de análise crítica, capacidade de criação e comunicação usando computadores. Com isso, o uso do computador para ensinar conceitos de Lógica de Programação de uma forma lúdica e adequada ao aluno, pode auxiliá-lo a resolver vários problemas em várias áreas do conhecimento (Zanetti, 2017).

\subsection{A ferramenta Scratch}

Temos no uso de ferramentas computacionais educativas, um estimulante para o aluno na aprendizagem, ajudando a desenvolver a capacidade de raciocínio lógico para a resolução de problemas. Através do fazer, superando desafios e com isso adquirindo conhecimento, vem gerar a aprendizagem, facilitando ao professor abordar conteúdos difíceis ao aluno entender apenas na teoria descontextualizada (Silva, 2015).

Uma dessas ferramentas é o Scratch, desenvolvida pelo MIT (Massachusetts Institute of Technology), com intuito de ajudar crianças a aprenderem programação de computadores sem ter que aprender a sintaxe complicada das linguagens de computador (Keshav, 2016).

A autora Keshav (2016), comenta sobre o destaque do Scratch por ser usado para auxiliar no desenvolvimento do pensamento crítico e planejado. Além disso, foi projetado para idades entre 8 a 16 anos com a ideia de aprendizagem e educação.

O Scratch se constitui como uma linguagem de programação, um software livre que permite ao usuário construir suas próprias histórias interativas, animações, jogos, simuladores, ambientes visuais de aprendizagem, músicas e arte. A forma de 
comando é a maneira que o usuário tem de expressar seu pensamento. A maneira de formar a programação do ambiente é através da visualização dos comandos por meio de blocos, que são arrastados para uma área específica e conectados (Sápiras; Vecchia; Maltempi, 2015).

O ambiente Scratch tem na programação visual, através de blocos que se encaixam como um quebra-cabeça, a possibilidade de exploração de diversos conceitos, perspectivas e práticas computacionais de forma criativa (Zanetti, 2017), auxiliando o aluno na aprendizagem através de conceitos de design.

Segundo Zanetti, 2017:

O aprendizado baseado no conceito de design é fundamentado em três conceitos:

1. Concepção: tornar o aprendiz capaz de criar, ao contrário de apenas utilizar ou interagir;

2. Personalização: trazer significado pessoal e relevante para algo criado;

3. Reflexão: usar as práticas criativas de cada um como forma de repensar e rever (Zanetti, 2017).

Além das habilidades essenciais que o aluno deve ter nos dias atuais, a habilidade de programar é fundamental, aprender estratégias para resolver problemas, desenvolver projetos e comunicar ideias é possível aprender através do Scratch. Com isso, a produção textual assistida pelo professor, pode proporcionar novos multiletramentos ao aluno com texto multimodal remixada, motivando a aprendizagem (Silva, 2015).

Devido a importação ou criação de mídia, é permitido construir histórias animadas e jogos com personagens. Além disso, pode-se compartilhar os projetos desenvolvidos para receber um feedback e que seja criada uma biblioteca de projetos, deixando o aluno mais encorajado (Zanetti, 2017).

Conforme Zanetti (2017), os comandos têm uma sintaxe simples, onde os blocos são divididos em nove classes: Movimento, Aparência, Som, Caneta, Controle, Operadores, Eventos, Sensores e Variáveis.

\section{Metodologia}

O artigo apresenta as etapas do projeto de uma pesquisa-ação na intervenção com robótica em uma escola pública, através dos encontros entre alunos, professores e os pesquisadores onde as atividades interativas e práticas de Robótica, a partir de sucatas e noções de programação por meio do Scratch, proporcionaram a interação e interatividade de todos os envolvidos. Foram sujeitos envolvidos, os alunos matriculados nos anos finais do ensino fundamental, os pesquisadores e professores de uma escola pública do Município de Cruz Alta, no Rio Grande do Sul.

Segundo Thiollent,

Uma pesquisa pode ser qualificada de pesquisa-ação, quando houver realmente uma ação por parte das pessoas ou grupos implicados no problema sobre observação. (Thiollent, 2011, p. 21).

$\mathrm{Na}$ pesquisa-ação os pesquisadores desempenham um papel ativo no equacionamento dos problemas encontrados, no acompanhamento e na avaliação das ações desencadeadas em função do problema (Thiollent, 2011, p. 21).

A proposta de cada oficina, foi apresentar situações que gerassem conhecimento sobre programação, utilizando-se do Scratch, e Robótica Educativa, analisando assim os processos e aprendizagens evidenciadas em cada atividade interativa.

Segundo Tripp (2005, p. 447), este método "requer ação tanto nas áreas da prática quanto da pesquisa, de modo que, em maior ou menor medida, terá características tanto da prática rotineira quanto da pesquisa científica".

Para Lévy (1993),

Cada grande inovação em informática abriu a passibilidade de novas relações entre homens e computadores: códigos de programação cada vez mais intuitivos, comunicação em tempo real, redes, micro, novos princípios de interfaces... 
É porque dizem respeito aos humanos que estas viradas na história dos artefatos informáticos nos importam (Lévy, 1993, p. 33).

A Robótica Educativa segundo os autores Cambruzzi e Souza (2015),

[...] Esta metodologia permite a participação ativa dos alunos no processo de aprendizagem, sem considerá-los espectadores do conhecimento, valorizando assim, suas experiências, envolvendo-os na análise, discussão e busca de soluções para os problemas apresentados (Cambruzzi; Souza, 2015, p. 24).

No contexto educacional das escolas públicas, as tecnologias estão presentes, o que sugere um olhar, tanto na questão da gestão, como pedagógica. A mediação das tecnologias digitais proporciona a interação, conforme Lévy (2000), "a interação de quaisquer pontos do espaço físico, social ou informacional". Segundo Lemos, "a cultura contemporânea, associada às tecnologias digitais (ciberespaço, simulações, tempo real, processos de virtualização, etc.), vai criar relação entre a técnica e a vida social que chamaremos de cibercultura." (Lemos, 2002, p.15). Para Kenski, "a cultura tecnológica exige uma evolução radical das maneiras de formação dos indivíduos, formar o julgamento, o senso crítico, o pensamento hipotético e dedutivo, as faculdades de observação e de pesquisa também estão associadas às mudanças tecnológicas e sociais” (Kenski, 2013, p. 61).

A cultura digital, como realidade presente, como proposta também à educação, passa a exigir novos conhecimentos, novas habilidades, tanto de professores, como dos alunos, refletindo-se em atualização e adaptação às mudanças contemporâneas. Segundo Lévy (2000), as ferramentas tecnológicas antes de mais nada são operadores da informação e que possibilitam mediação de conhecimento e interação.

Assim, a utilização de software como mediadores para aprendizagem, [...] a utilização da Robótica como um recurso educacional se torna uma estratégia que pode colaborar[...] (Machado, et al., 2018, p. 224) para professores e alunos desenvolverem competências e habilidades exigidas pela cultura digital.

Segundo Papert,

A habilidade mais determinante do padrão de vida de uma pessoa é a capacidade de aprender novas habilidades, assimilar novos conceitos, avaliar novas situações, lidar com o inesperado. Isso será cada vez mais verdadeiro no futuro: a habilidade para competir tornou-se a habilidade de aprender (Papert, 2008, p. 13).

Nesta lógica, o estudo propôs o uso do software Scratch de maneira educativa, ao proporcionar um aprendizado baseado na prática cooperativa, com a intenção de desenvolver no aluno a capacidade de pensar, buscar, achar soluções para atividades, bem como aos novos desafios propostos. Diante de uma sociedade de informação, processada rapidamente, o que exige melhorar as habilidades de raciocínio se torna uma necessidade.

O papel do professor e do aluno são importantes para que aconteça a integração das tecnologias no uso pedagógico e para que se concretize como uma proposta de mudança nas concepções educativas. Mas relevante também é proporcionar aos alunos oportunidades de adquirir conhecimento e habilidades, para interatividade com tecnologias e reconhecer suas potencialidades. Como salienta Kenski (2013), que em princípio, devemos compreender e nos apropriarmos das especificidades das inovações tecnológicas, adequando-as a inovações.

Segundo Perrenoud,

[...] as escolas não podem mais ignorar o que se passa no mundo, que o desenvolvimento de novas tecnologias da informação e da comunicação transformam espetacularmente não só como se comunicar, mas também, a forma de trabalhar, de decidir e de pensar (Perrenoud, 2000, p. 125). 
A primeira etapa da pesquisa-ação foi iniciada com uma reunião com a direção e coordenação pedagógica da escola participante do projeto, para expor o projeto, obtenção de autorização e parceria para a realização do projeto piloto de Robótica Educativa e de Scratch para alunos da Educação Básica, dos anos finais do Ensino Fundamental. Neste primeiro contato foi enfatizado o objetivo de proporcionar atividades práticas e noções de Robótica Educativa e do pensamento computacional como incentivo à motivação a fim de desenvolver nos alunos, novas competências como a compreensão, o pensar, o buscar soluções, a criatividade, julgamento, tomada de decisões, cooperação e colaboração, por intermédio de tais metodologias.

A coordenação pedagógica da escola em reunião com os professores definiu critérios para determinar quais os alunos que iriam participar das oficinas nesta primeira etapa do projeto, já que foi grande o interesse por parte dos alunos em participar dos encontros e das atividades práticas.

Como segunda etapa, poderíamos citar, a organização documental, necessária para a dinâmica dos encontros, no laboratório de informática da escola e com os alunos fora do horário regular de aula, o que demandou vários encaminhamentos. Para tanto, por intermédio da coordenação pedagógica da escola, os pais ou responsáveis receberam a documentação, explicando todos os detalhes, como objetivo do Projeto, tempo de duração do Projeto, dia da semana, horário de início e término de cada encontro, assim como, uma ficha de autorização, a qual exigia a assinatura dos pais ou responsáveis, autorizando e concordando com a frequência do aluno no Projeto. Posteriormente foram organizadas as listas de presença para cada oficina.

Em um terceiro momento, ocorreu o desenvolvimento das oficinas práticas, com a cooperação e colaboração de todos os envolvidos. Para um melhor acompanhamento e registro das atividades desenvolvidas nas oficinas, adotou-se os seguintes itens para observações: atividades desenvolvidas, envolvidos, objetivos da oficina, e aspectos observados.

Optou-se por adicionar na pesquisa a captura e apreciação de dados visuais, em especial das fotos tiradas durante as interações e interatividades ao longo das oficinas, "documentar ou subsequentemente analisar aspectos da vida social e interações sociais" (Banks, 2009, p.19). Esta corrente se refere ao "uso de imagens para estudar a sociedade" (Banks, 2009, p.21). Aqui aplica-se por se tratar de pesquisa de aspectos relacionados a cultura digital, onde a fotografia é meio documental e passível de análise de "uma conexão social e pessoal com as imagens" (Banks, 2009, p.21), na investigação da realidade das oficinas.

\section{Resultados}

\subsection{Descrição das atividades e aspectos observados}

Como ferramentas para apresentação desta análise, inicialmente recorreremos a dados coletados a partir das observações feitas pelos pesquisadores durante o desenvolvimento das atividades práticas nas oficinas, e que estão descritas e detalhadas a seguir. Neste detalhamento, procurou-se descrever as atividades desenvolvidas, os objetivos, os envolvidos e os aspectos observados nas 15 oficinas realizadas.

\subsubsection{Oficina 1: oficina de apresentação}

- Atividades desenvolvidas: Dinâmica de apresentação do grupo de professores envolvidos e dos alunos participantes. Informação detalhada de como será processo e desenvolvimento das oficinas. Recolher documentação de autorização dos pais ou responsáveis, para a participação das oficinas em turno inverso ao das aulas regulares.

- Envolvidos: Pesquisadores; Professores; Alunos.

- Objetivos da oficina: Apresentar e informar sobre o Projeto; enfatizar os objetivos das oficinas; recolher documentação de autorização de participação. 
- Aspectos observados: Neste primeiro encontro, os alunos demonstraram muita curiosidade, e certa ansiedade em relação às oficinas. Os Professores que participaram deste primeiro encontro, enfatizaram a necessidade de projetos neste enfoque, para maior envolvimento dos alunos em relação ao uso de tecnologias para suas aprendizagens.

\subsubsection{Oficina 2 - conhecendo a linguagem Scratch}

- Atividades desenvolvidas: Oficina explicativa e demonstrativa, com auxílio da conexão do computador a um projetor, o Professor orientador mostrou as diversas possibilidades sobre a Linguagem Scratch, mostrando os comandos principais da linguagem.

- Envolvidos: Pesquisadores; Professores; Alunos.

- Objetivos da oficina: Mostrar e demonstrar ao aluno o potencial dessa linguagem para desenvolver jogos, histórias e animações.

- Aspectos observados: Percebeu-se uma grande motivação por parte dos alunos, ao interagiram com os colegas, bem como, na interatividade com o Software Scratch. Demonstraram interesse pela linguagem de programação do Scratch. Com facilidade a maior parte dos alunos, desenvolveram as atividades de comandos propostas.

\subsubsection{Oficina 3 - oficina de movimentação e animação}

- Atividades desenvolvidas: Oficina explicativa e demonstrativa, com auxílio da conexão do computador a um projetor, o Professor orientador mostrou as diversas possibilidades de criação de uma animação através de comandos da caixa "Movimento" na área de blocos.

- Envolvidos: Pesquisadores; Professores; Alunos.

- Objetivos da oficina: Entender de que maneira se dá a movimentação através de números, em duas retas (X, Y) que dão origem ao plano cartesiano.

- Aspectos observados: Os alunos entenderam a movimentação e com como funciona o plano cartesiano relacionando com a matemática. Demonstraram desenvoltura para criarem animação por meio da organização de comandos na caixa Movimento no Software.

\subsubsection{Oficina 4 procedimentos seguros para desmontar sucatas}

- Atividades desenvolvidas: O Professor orientador mostrou as possibilidades e como fazer um esboço de Robô com sucatas. Atividade interativa a partir das explicações e ensinamentos do professor orientador, em relação aos cuidados e precauções necessárias antes de iniciar o trabalho com sucatas, principalmente com sucatas eletrônicas. Oficina explicativa, demonstrativa e de escolha do material para o projeto do Robô.

- Envolvidos: Pesquisadores; Professores; Alunos.

- Objetivos da oficina: Conscientizar os alunos da importância de conhecer sobre as práticas e cuidados necessários ao trabalhar a Robótica Educacional com sucatas eletrônicas. Propor aos alunos pensar, projetar e iniciar seu Robô.

- Aspectos observados: Os alunos demonstraram atenção e comprometimento, com a atividade proposta. Foram sociáveis com os colegas e com os professores, procuraram esclarecer suas dúvidas, demonstrando também desenvoltura e habilidades no decorrer da atividade de desmontar as sucatas e organizar as peças que fariam parte de seus projetos de Robô. 


\subsubsection{Oficina 5 - conhecer noções do pensamento computacional}

Atividades desenvolvidas: Com auxílio da conexão do computador a um projetor, o Professor orientador mostrou através de um jogo como é o pensamento computacional através de comandos que levam um personagem no labirinto até a saída, pelo caminho assinalado onde os comandos são blocos que encaixam uns nos outros.

- Com auxílio da conexão do computador a um projetor, o Professor orientador mostrou as diversas possibilidades.

- Envolvidos: Pesquisadores; Professores; Alunos.

- Objetivos da oficina: Criar a partir do pensamento computacional e de sucata. Compreender o que é algoritmo e que os computadores necessitam de instruções precisas, para assim evitar erros.

\subsubsection{Oficina 6 - cenário e troca de palco no Scratch}

- Atividades desenvolvidas: Com auxílio da conexão do computador a um projetor, o Professor orientador mostrou as diversas possibilidades de criação de cenários e troca de palco, personagens e objetos. Atividade: cada aluno em um computador, exercitaram a troca de cenário, palco, objetos e personagens, criaram também, assim os primeiros esboços para futuras histórias.

- Envolvidos: Pesquisadores; Professores; Alunos.

- Objetivos da oficina: Usar comandos específicos para troca de cenário, palco e desenhar objetos e personagens.

- Aspectos observados: Identificamos facilidade por parte dos alunos, que demonstraram habilidades ao interagir com o software, ao realizarem os exercícios propostos de escolha e troca de cenários, de personagens e objetos.

\subsubsection{Oficina 7 - criando uma história}

- Atividades desenvolvidas: Atividade de interatividade com o software Scratch, cada aluno em um computador. Breve retomada dos aspectos trabalhados na oficina anterior. Esclareceu as dúvidas que surgiram. Cada aluno recebeu a descrição e orientação da atividade de criação de história animada, por escrito. Como culminância, os alunos sentados em círculo relataram os aspectos que encontraram dificuldades e quais ainda precisavam de acompanhamento, bem como o que consideraram interessantes.

- Envolvidos: Pesquisadores; Professores; Alunos.

- Objetivos da oficina: Incentivar a aplicação de habilidades e conhecimentos já adquiridos pelos alunos, para criação de uma história animada pelas possibilidades do Scratch.

- Aspectos observados: Observou-se a criatividade por parte dos alunos em desenvolver histórias animadas com os recursos do Scratch, buscando sempre o recurso que melhor se identificasse com o enredo da história criada. Também percebemos a interação entre os alunos ao relatarem no grande grupo dificuldades que tiveram. Entre elas destacamos a mais citada pelos alunos, que foi escolher o tema da história, pois pensaram vários. Todos relataram ter gostado da interatividade proposta pela oficina.

\subsubsection{Oficina 8 - aplicações práticas de ciclos e condições}

- Atividades desenvolvidas: Oficina explicativa e demonstrativa, com auxílio da conexão do computador a um projetor, o Professor orientador. Ensinado as aplicações práticas de ciclos os diversos comandos de condições para o aperfeiçoamento das histórias criadas.

- Envolvidos: Pesquisadores; Professores; Alunos. 
- Objetivos da oficina: Identificar os comandos lógicos e condicional e suas possibilidades quando usados para a programação determinando as opções de escolha dos personagens criados.

- Aspectos observados: Alguns alunos tiveram dificuldades, mas entenderam as expressões lógicas através da execução de comandos no Scratch.

\subsubsection{Oficina 9 - escolha de materiais e montagem seu projeto de robótica}

- Atividades desenvolvidas: Identificação de componentes em sucatas e montagem dos Robôs. Atividade cooperativa e colaborativa, com envolvimento dos professores orientadores e dos alunos.

- Envolvidos: Pesquisadores; Professores; Alunos.

- Objetivos da oficina: Montar seus projetos de Robô, com as peças extraídas de sucatas, como fontes de computadores, controles remotos e demais peças. Empregar conhecimentos adquiridos e realizar seus projetos. Cooperar com os colegas para montagem dos Robôs.

- Aspectos observados: Os alunos participaram com entusiasmo para a criação e montagem dos projetos de Robô com sucatas. Criações como Robô escova, Robô ventilador, protótipo de carrinho.

\subsubsection{Oficina 10 - usando comando sensores}

- Atividades desenvolvidas: Atividade de interatividade a partir do software Scratch. Oficina explicativa e demonstrativa, sobre a caixa "Sensores", ferramenta para avaliar quando um botão do mouse ou uma tecla é pressionada, como possiblidade de testagem.

- Envolvidos: Pesquisadores; Professores; Alunos.

- Objetivos da oficina: Incentivar os alunos a entender, testar tudo exaustivamente, para eliminar a maior quantidade possível de erros. Pensar que podemos aprender com os erros, para corrigi-los.

- Aspectos observados: Percebeu-se que no decorrer desta oficina os alunos se empenharam em encontrar os erros e as possibilidades para corrigi-los com base na detecção do erro, ou seja, os alunos aprenderam com os seus erros.

\subsubsection{Oficina 11 - labirinto}

- Atividades desenvolvidas: Com o acompanhamento dos professores orientados e usando os computadores do laboratório de Informática os alunos começaram a desenhar um labirinto para usar os comandos setas. Atividade de interatividade a partir do software Scratch.

- Envolvidos: Pesquisadores; Professores; Alunos.

- Objetivos da oficina: Estimular o aluno a aprender a fazer desenhos e a movimentar o personagem tendo limites no palco.

- Aspectos observados: Nesta décima primeira oficina, percebemos que os alunos estavam bem familiarizados tanto com os professores orientadores como com os propósitos das oficinas, mas principalmente com o software Scratch. Os alunos conseguiram desenvolver objetos que limitavam o personagem na movimentação.

\subsubsection{Oficina 12 - criando um jogo - livre}

- Atividades desenvolvidas: A partir das orientações do professor orientador os alunos devem buscar o computador e iniciar a criação do seu jogo.

- Envolvidos: Pesquisadores; Professores; Alunos. 
- Objetivos da oficina: Criar um jogo a partir dos conhecimentos adquiridos. Dar continuidade ou criar do zero um jogo com tema livre.

- Aspectos observados: Os alunos demonstraram entusiasmo e envolvimento ao realizarem a atividade de construção de um jogo, manifestando cooperação e interação com os demais colegas.

\subsubsection{Oficina 13 - criando a arte do grupo de robótica}

- Atividades desenvolvidas: Atividade em grupo. Reunidos em grupos discutiram com irão criar a arte. Foi ressaltado aos alunos que a atividade deveria ser cooperativa no grupo. Incentivo para criarem uma arte para o grupo. Ao término, apresentarão ao grande grupo. Cada pequeno grupo fará a defesa da sua arte, sua criação. No final das apresentações, por votação foi escolhida a arte para o grupo.

- Envolvidos: Pesquisadores; Professores; Alunos.

- Objetivos da oficina: Incentivar os alunos a criarem uma arte para caracterizar o Grupo de alunos participantes desta edição do projeto. Observando princípios de cooperação e colaboração entre os participantes do grupo.

- Aspectos observados: Os alunos demonstram interesse e criatividade ao criarem uma arte para identificar o grupo participante das oficinas.

\subsubsection{Oficina 14 - construção de cenários, pensamento lógico}

- Atividades desenvolvidas: Em grupos os alunos organizaram seus cenários, obedecendo aspectos relacionados ao pensamento computacional e testaram seu Robôs.

- Envolvidos: Pesquisadores; Professores; Alunos.

- Objetivos da oficina: Observar a participação, criatividade, relacionamento com colegas no decorrer da atividade.

- Aspectos observados: Os alunos com desinibição construíram os cenários, apresentando e testando seus projetos. Interessante, as atitudes de respeito com o trabalho dos colegas. Os alunos mostraram amadurecimento e respeito ao expressar suas opiniões no grupo em relação aos projetos dos demais participantes.

\subsubsection{Oficina 15 - apresentação dos trabalhos}

- Atividades desenvolvidas: Atividade de socialização.

- Envolvidos: Pesquisadores; Professores; Alunos.

- Objetivos da oficina: Valorizar a participação e divulgar o trabalho desenvolvido pelos alunos.

- Aspectos observados: Notou-se que os alunos apresentaram suas criações com desenvoltura e reconhecimento de que as oficinas de Robótica Educativa foram importantes para sua aprendizagem.

\subsection{Registro visual - uma realidade fotografada}

No decurso das oficinas, adotou-se o registro por fotografias, permitindo assim, registrar as iniciativas, interatividades e interações. O registro através de fotos, foi muito significativo para contextualizar visualmente, pois mostra também os aspectos de interatividade entre professores orientadores e os alunos. "A fotografia vem sendo usada para documentar" (Banks, 2009, p. 21).

As fotos propiciaram aos pesquisadores relembrar a participação, perspectivas e iniciativas dos alunos nas atividades práticas propostas para cada oficina "[...] metodologias de pesquisa visual tendem mais a pesquisa exploratória do que ao confirmatório". “[...]. É um método destinado a levar o pesquisador a esferas que ele pode não ter considerado e em direção à descoberta que não tinha sido prevista" (Banks, 2009, p. 24). 
A fotografar o decorrer das oficinas, possibilitou aos pesquisadores, o armazenamento de tais recursos visuais, viabilizando um revisitar das atividades por intermédio das imagens documentas nas fotografias, permitindo rever, relembrar de situações vivenciadas nas oficinas, não guardadas na memória.

Assim, numa sequência destacada destas fotografias as figuras abaixo, Figura 1 (a, b, c) e Figura 2 (a, b, c) trazem um pouco do contexto das oficinas, quando os alunos descobriam e desenvolviam atividades a partir do Software Scratch.

Figura $1(\mathbf{a}, \mathbf{b}, \mathbf{c})$ - Conhecendo o Scratch.
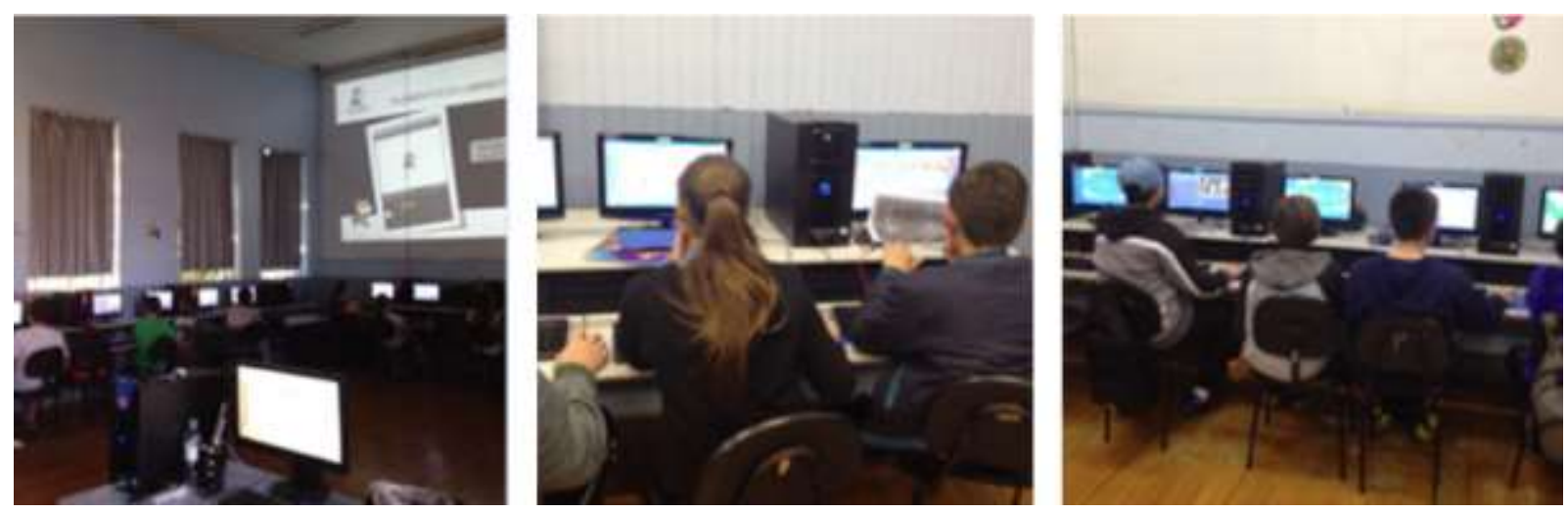

Fonte: Pesquisadores autores.

Figura 2 (a, b, c) - Construção de um jogo.
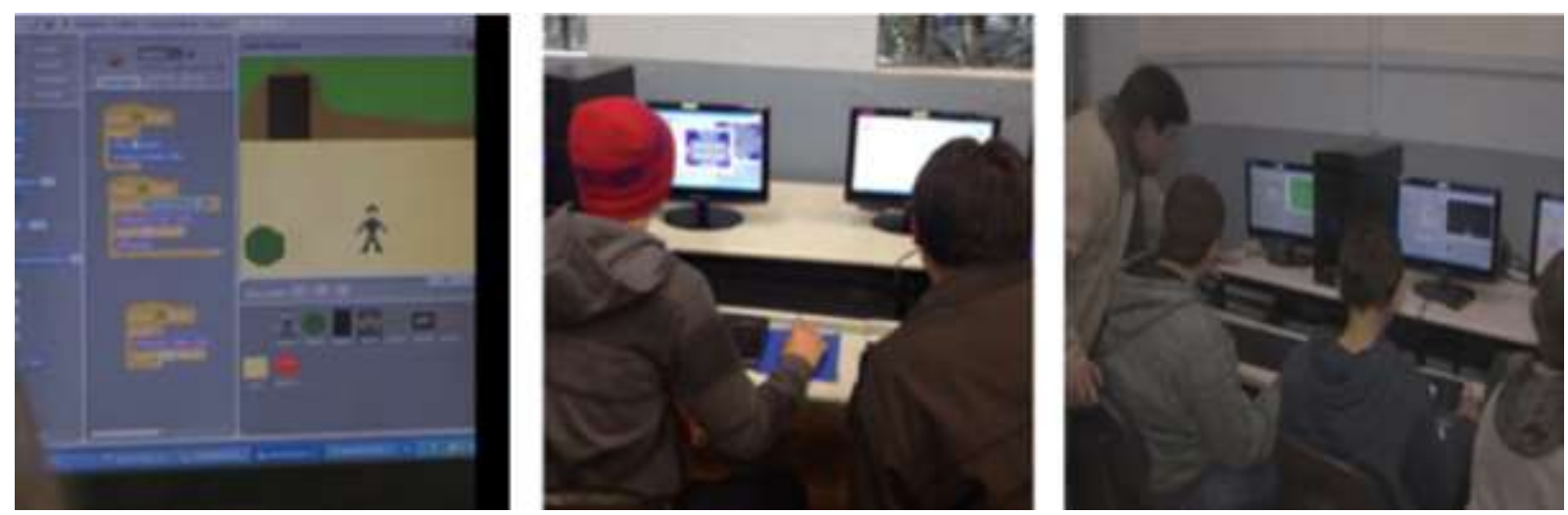

Fonte: Pesquisadores autores.

Ainda valendo-se do registro fotográfico, a Figura 3 (a, b, c) e Figura 4 (a, b, c), trazem registro das oficinas, que permite o relembrar das interações dos alunos durante as atividades práticas, propostas no projeto de Robótica Educativa. E enquanto recebiam as orientações técnicas, necessárias para o manuseio de sucatas eletrônicas, bem como, os cuidados que deveriam ter durante as oficinas práticas. Os alunos também se demonstraram participativos enquanto o professor orientador, fez demonstrações das possibilidades de montagem de robô com sucatas eletrônicas.

Os participantes interagiram durante a escolha de materiais para seu projeto de robótica, conforme Figura 4 (a, b, c), demonstrando respeito aos colegas e cooperação para a realização dos projetos de todos.

$\mathrm{Na}$ oficina de construção de cenários temáticos, para atividades relacionadas ao pensamento computacional, demonstrados na Figura 3 (b, c) envolveram-se de maneira criativa e com muita motivação. 
Figura 3 (a, b, c) - Criação dos projetos.
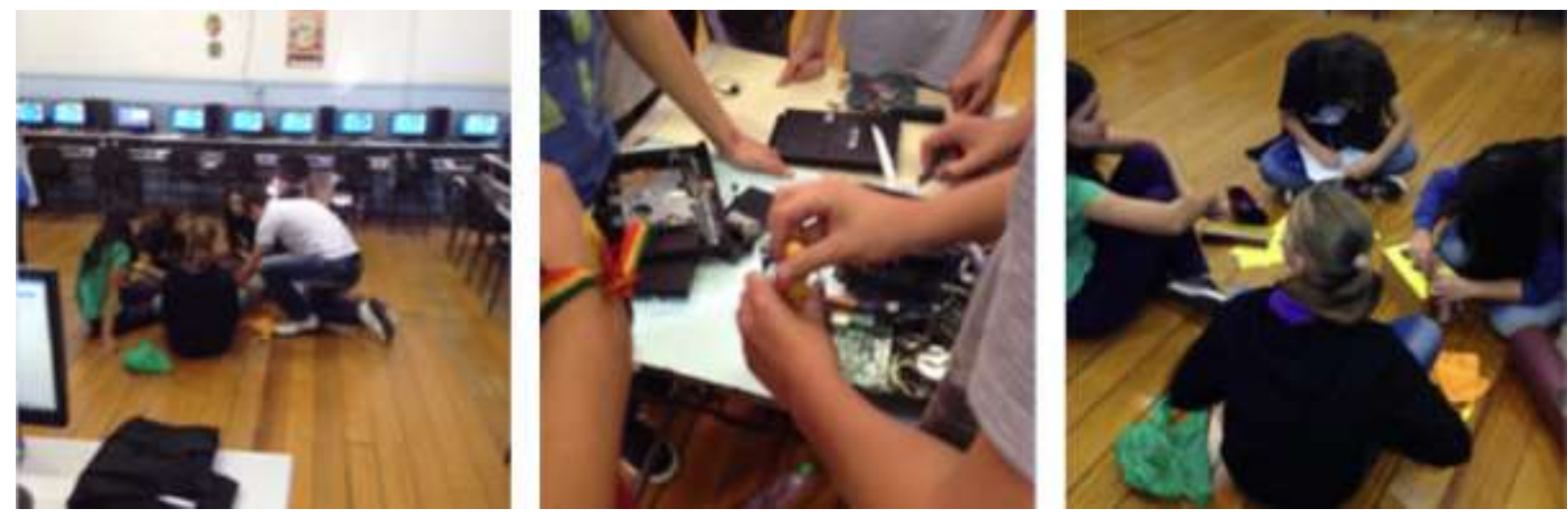

Fonte: Pesquisadores autores.

Figura 4 (a, b, c) - Escolha de materiais para construir o Robô.
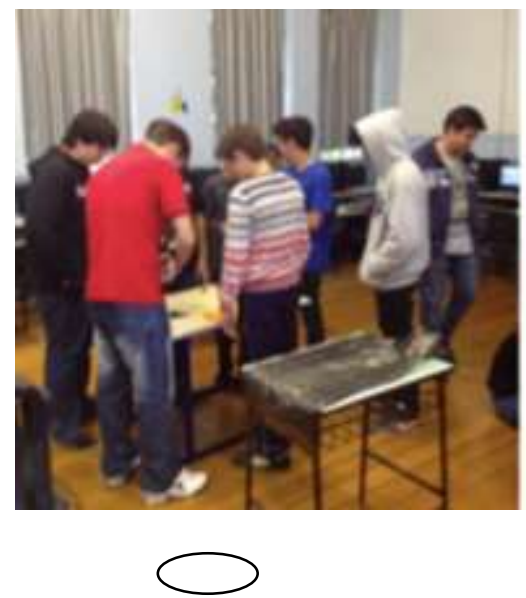

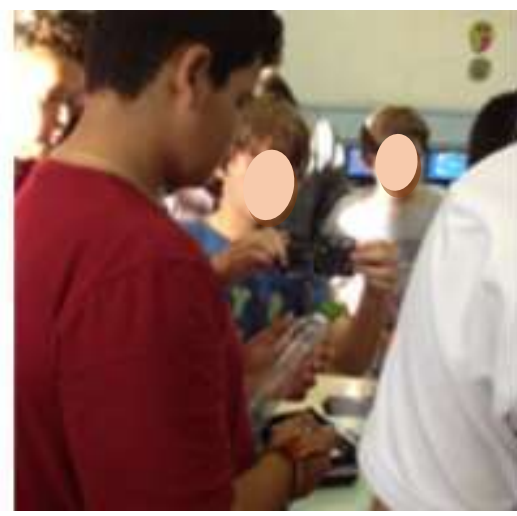

Fonte: Pesquisadores autores.

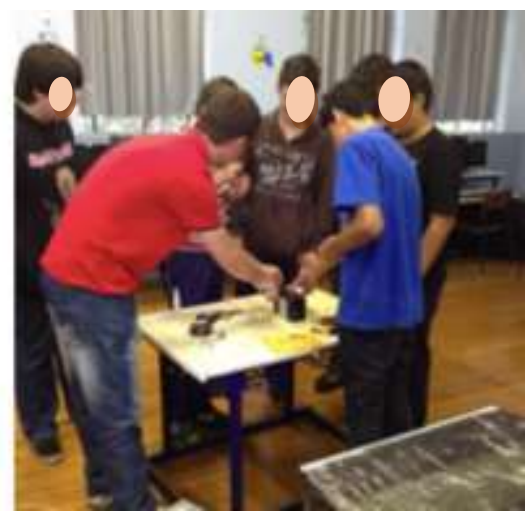

Ainda, com os recursos da fotografia, aqui mostrados nas Figura 5 (a, b, c) e na Figura 6 (a, b, c), é possível acompanhar por esse recurso visual, um pouco dos momentos onde os alunos socializaram para o grande grupo os Robôs construídos, a partir das noções da Robótica Educativa e de seus conhecimentos e habilidades já adquiridos anteriormente.

Figura 5 (a, b, c) - Apresentação dos Robôs.
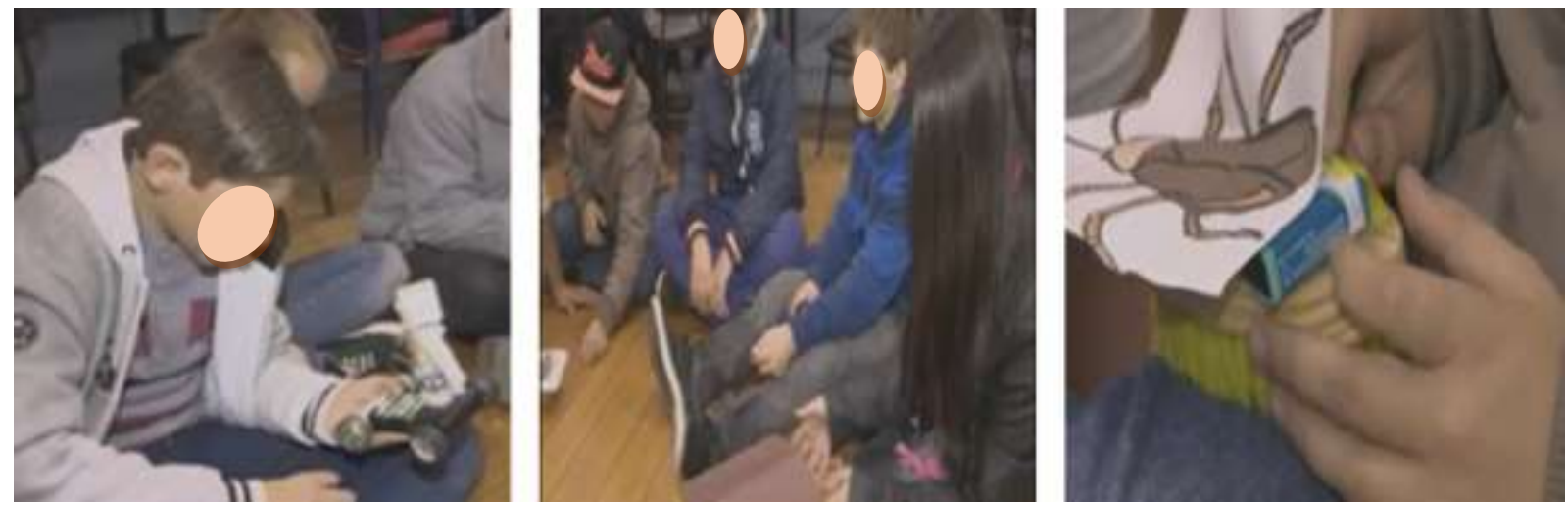

Fonte: Pesquisadores autores. 
Figura 6 (a, b, c) - Demonstração dos Robôs.
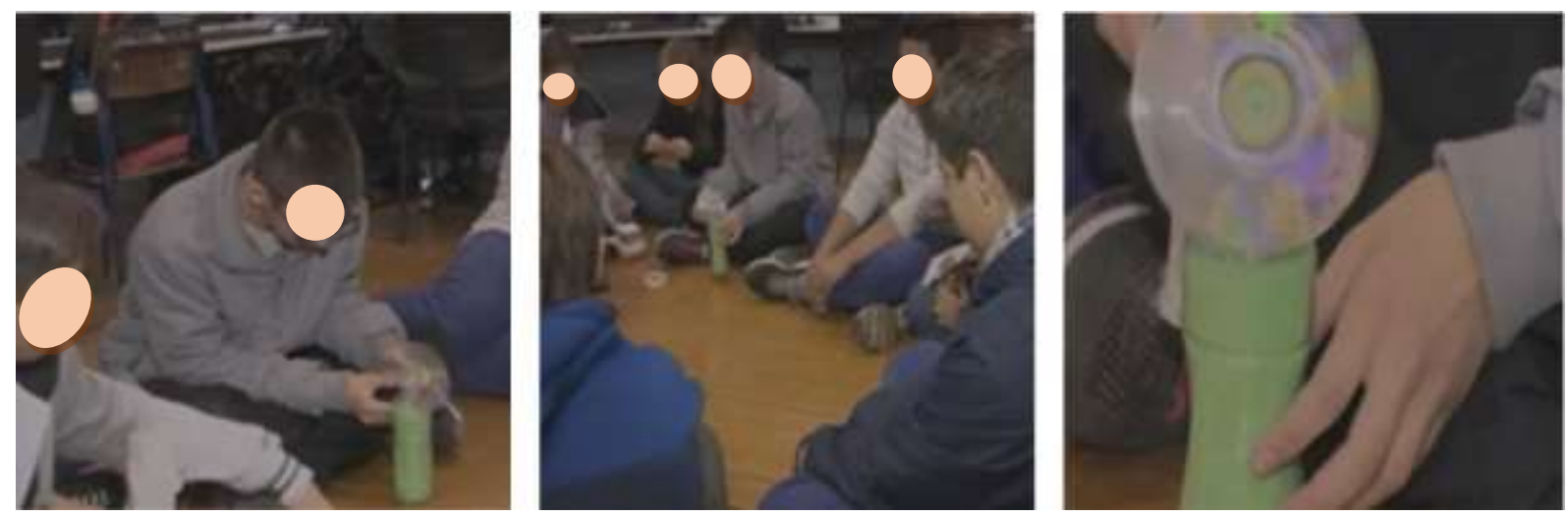

Fonte: Pesquisadores autores.

$\mathrm{Na}$ oficina, criando a arte do grupo de robótica, os alunos apresentaram os resultados esperados, desenvolveram a atividade com entusiasmo demonstrando atitudes de cooperação e colaboração no grupo. A Figura 7, traz as imagens das artes que os pequenos grupos criaram para representar Grupo de Robótica.

Figura 7 - Criando a arte para o Grupo.
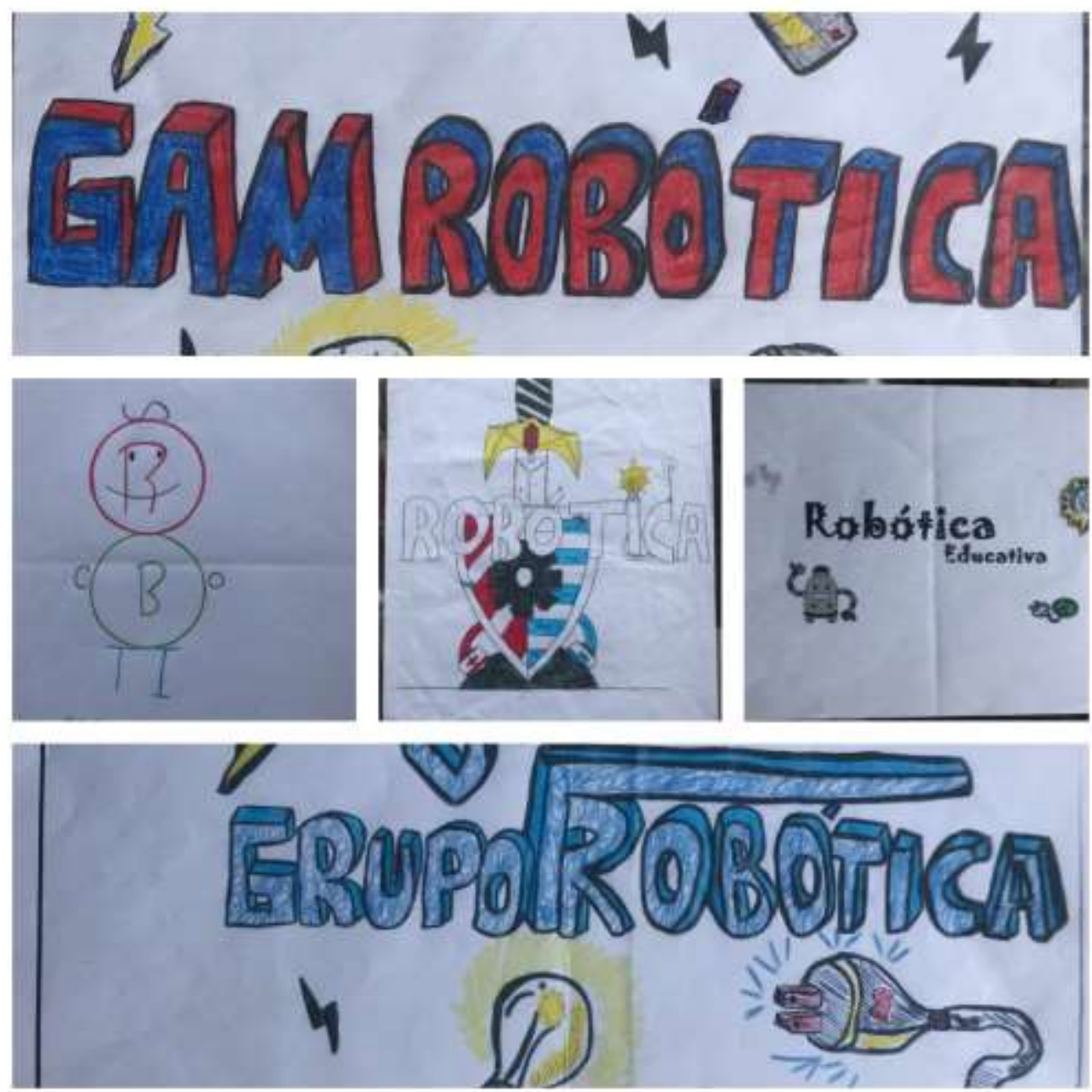

Fonte: Pesquisadores autores. 


\section{Considerações Finais}

Como uma proposta de interdisciplinaridade, a Robótica Educativa se apresenta como uma estratégia, que favorece a integração de conceitos de várias áreas do conhecimento. Promovendo a oportunidade aos professores para desenvolverem projetos interdisciplinares, com o envolvimento dos alunos, propondo oportunidades para aplicarem seus conhecimentos e habilidades anteriormente adquiridos.

Permite que os alunos usem materiais diversos, testando-os, modelando-os até mesmo simulando por meio de modelos o real. A Robótica Educativa, pode se transformar em um incentivo a mais nos processos de ensinar e de aprender, aproximando as concepções de tecnologia e ciência no contexto da aprendizagem.

Ao término do estudo, podemos considerar que se atingiu os objetivos propostos para as atividades no Software Scratch, como nas atividades práticas de Robótica Educativa e do pensamento computacional, como incentivo para despertar a motivação ao pensar, ao buscar soluções, a criatividade, julgar, tomar decisões, cooperar e colaborar no trabalho em grupo, pois percebeu-se, tais competências e habilidades nos alunos sempre que necessário na resolução das atividades propostas.

Atividade que ajuda o aluno a superar seus limites em relação a comunicação no grupo, contribui para que o aluno verbalize suas experiências, conhecimentos e sugestões, desenvolvendo as capacidades de dialogar, opinar e respeitar a opinião dos outros.

Entende-se, porém, que para se tornar uma realidade, a Robótica Educacional e o pensamento computacional, ser adotado nos espaços escolares, passa pela apropriação por parte dos professores de tais conhecimentos e habilidades, para que adotem metodologias, procedimentos favorecendo o aprender a aprender dos alunos, despertando a curiosidade, a criatividade, o raciocínio lógico, o pensar a partir do conhecimento já adquirido.

\section{Referências}

Banks, M. (2009). Dados visuais para pesquisa qualitativa. Artmed.

Blikstein, P. O Pensamento Computacional e a Reinvenção do Computador na Educação. http://bit.ly/11XlbNn.

Brackmann, C. P. (2017) Desenvolvimento do Pensamento Computacional através de atividades desplugadas na Educação Básica. https://lume.ufrgs.br/handle/10183/172208.

Cambruzzi, E., \& Souza, R. M. de. (2015). Robótica Educativa na aprendizagem de Lógica de Programação: Aplicação e análise. Anais do XXI Workshop de Informática na Escola (WIE 2015), 1, 21, 2015. https://www.br-ie.org/pub/index.php/wie/article/view/4981.

Castells, M. (2013). Comunicación y poder. México: Siglo XXI Editores.

Kenski, V. M. (2013). Tecnologias E Tempo Docente. Campinas, Papirus.

Keshav, K. (2016). Codificação, é realmente uma brincadeira de criança agora. THE HINDU Bangalore. https://www.thehindu.com/sci-tech/ technology/Coding-it-really-is-child\%E2\%80\%99s-play-now/article12149670.

Lévy, P. (2000). Cibercultura. (2a ed.), Ed. 34.

Lévy, P. (1993). As Tecnologias da Inteligência. Tradução de Carlos Irineu Costa. Editora 34 LTDA.

Machado, A., Câmara, J., \& Willians, V. (2018). Robótica Educacional: Desenvolvendo Competências para o Século XXI. Cultura Maker na Escola. http://ceur-ws.org/Vol-2185/CtrlE_2018_paper_50.pdf, p. 215-226.

Mesquita, J. dos S. N., \& Albrecht, M. P. S. (2019). Construção de brinquedos em aulas de Robótica Educacional aliadas ao Ensino de Ciências. Research, Society and Development, 8(5), e4285677. https://rs djournal.org /index.php /rsd/ article/view/677.

Paula, B. H. De, Valente, J. A., \& Burn, A. (2014). O uso de jogos digitais para o desenvolvimento do currículo para a educação computacional na Inglaterra. Currículo sem Fronteiras, 14(3), 46-71.

Papert, S. (1980). Mindstorms: Children, computers, and powerful ideas. Basic Books.

Papert, S. (2008). A Máquina Das Crianças: Repensando A Escola Na Era Da Informática. Edição Revisada.. Artmed.

Perrenoud, P. (2000). Dez Novas Competências Para Ensinar.: Artes Médicas Sul. 
Research, Society and Development, v. 10, n. 3, e20010313076, 2021

(CC BY 4.0) | ISSN 2525-3409 | DOI: http://dx.doi.org/10.33448/rsd-v10i3.13076

Quitián, S., \& González, J. (2020). Aspectos pedagógicos para ambientes Blended-Learning. Hamut’ay, 7(1), 48 - 59.

Sápiras, F. S., Vecchia, R. D., \& Maltempi, M. V. (2015). Utilização do Scratch em sala de aula. CEAMECIM. Educ. Matem. Pesq. 17(5), 973 - 988. https://ceamecim.furg.br/images/Lemafi-Educ/artigos oficina_scratch/scratch_sala_de_aula.pdf.

Rosa, V, Coelho Neto, J. (2020). Design Thinking e o Pensamento Computacional e suas articulações para o ensino de Robótica Educacional: uma revisão. Research, Society and Development, 9(10), e6659109019. 10.33448/rsd-v9i10.9019. https://rsdjournal.org/index.php/rsd/article/view/9019.

Silva, P. L. E. (2015). Análise do Scratch para ensino-aprendizagem de lógica de programação: experimento pedagógico-didático no curso Técnico de Informática do Instituto Federal De Educação, Ciência e Tecnologia de Goias, Câmpus Inhumas. Bacharelado em Informática. Instituto Federal De Educação, Ciência e Tecnologia de Goiás, Câmpus de Inhumas, Inhumas - GO. https://repositorio.ifg.edu.br /bitstream/prefix /157/1/Monografia $\% 20 \% 28$ Final $\% 29 \% 20 \% 281 \% 29$.pdf.

Stumpenhorst, J. (2018) A nova revolução do professor. Editora Vozes.

Thiollent, M. (2011). Metodologia da Pesquisa-Ação (18a ed.), Cortez.

Tripp, D. (2005). Pesquisa-ação: uma introdução metodológica. Educação e Pesquisa, 31(3), 443-466. https://www.scielo.br/pdf/ep/v31n3/a09v31n3.pdf

Wing, J. M. (2006). Computational Thinking. Communications of the ACM, 49(3). https://www.cs.cmu.edu/ 15110-s13/ Wing06-ct.pdf.

Wing, J. M. (2008). Computational thinking and thinking about computing. Philosophical Transactions of the Royal Society A: Mathematical, Physical and Engineering Sciences, 366(1881), 3717-3725.

Zanetti, H. A. P. et al. (2017) Proposta De Ensino De Programação Para Crianças Com Scratch E Pensamento Computacional. Tecnologias Sociedade E Conhecimento, Campinas, 4, www.Nied.Unicamp.Br/Ojs/.

Vicari, R. M., Moreira, Á., \& Menezes, P. B. (2018). Pensamento computacional: revisão bibliográfica. Projeto UFRGS/MECTED 676559/SAIFI - Avaliação de Tecnologias Educacionais. V. 02. https://lume.ufrgs.br/bitstream/handle /10183/197566/001097710.pdf?sequence=1\&isAllowed=y . 